\title{
Study on Corrosion Properties and Microstructure of PEO Coatings Formed on AZ31 Mg Alloy
}

\author{
Yuanji. Shi ${ }^{1, *}$, Junwan Li $^{2}$, Hongjun Wang ${ }^{1}$, Hongchun Teng ${ }^{1}$ \\ ${ }^{1}$ Department of Mechanical Engineering, Nanjing Institute of Industry Technology, Nanjing Jiangsu \\ 210046, China; \\ ${ }^{2}$ School of Materials Science and Engineering, Shanghai University, Shanghai 200072, China. \\ *E-mail: yuanji_shi@hotmail.com
}

doi: $10.20964 / 2020.06 .39$

Received: 6 February 2020 / Accepted: 18 March 2020 / Published: 10 May 2020

\begin{abstract}
Plasma electrolytic oxidation(PEO) coatings were fabricated on AZ31 Mg alloy in phosphate-silicate based electrolyte with additive $\mathrm{K}_{2} \mathrm{ZrF}_{6}$. The physical and chemical properties of the coatings were studied by SEM, AFM, XRD, XPS, potentiodynamic polarization and electrochemical impedance spectroscopy (EIS) test. The attained results showed that the thickness of the PEO coatings linearly increased with the increment treatment time. Besides, the micropores and corrosion resistance of the coatings varied with the PEO treatment time. The XRD presentation proved that the coatings were mainly composed of $\mathrm{MgO}, \mathrm{MgF}_{2}, \mathrm{MgSiO}_{3}$ and $\mathrm{ZrO}_{2}$. Moreover, the EIS results matched well with the potentiodynamic polarization test results.
\end{abstract}

Keywords: AZ31 Mg alloy; Corrosion; Potentiodynamic polarization; PEO Coatings; EIS

\section{FULL TEXT}

(C) 2020 The Authors. Published by ESG (www.electrochemsci.org). This article is an open access article distributed under the terms and conditions of the Creative Commons Attribution license (http://creativecommons.org/licenses/by/4.0/). 